\title{
The Spatiotemporal Changes of Oxygen Consumption Rate and Heat Release Intensity During Coal Spontaneous Combustion
}

\author{
Yongfei Jin ${ }^{1,2}$, Li Yan ${ }^{1,2 *}$, Yin Liu ${ }^{1,2}$, Chuansheng $\mathrm{Li}^{1}$ \\ ${ }^{1}$ School of Safety Science and Engineering, Xi'an University of Science and Technology, Xi'an 710054, China \\ ${ }^{2}$ Mine and Hazard Prevention and Control in the Key Laboratory of Western China, Ministry of Education, Xi'an 710054, \\ China
}

Corresponding Author Email: 20120089024@stu.xust.edu.cn

https://doi.org/10.18280/ijht.390427

Received: 5 April 2021

Accepted: 28 June 2021

\section{Keywords:}

coal spontaneous combustion, high temperature point, oxygen consumption rate, heat release intensity

\begin{abstract}
In order to study the dynamic development law of different regions in the spontaneous combustion process of coal, the spontaneous combustion process of loose coal under constant air volume from normal temperature to $140{ }^{\circ} \mathrm{C}$ was tested by using large coal spontaneous combustion simulation test bench, so as to analyze the change law of oxygen consumption rate and heat release intensity in time and space. The results showed that the temperature of the loose coal spontaneous combustion process varies with the height of the coal body at different temperature stages. The high temperature point moved from the upper middle position of the coal body to the air inlet side; the oxygen consumption rate and time of different coal body heights showed indexes Increase, and the rate of oxygen consumption coincided with the migration law of the high temperature point of the coal body height. The coal body exhibited slow and rapid growth in stages around $75{ }^{\circ} \mathrm{C}$; the heat release intensity of the loose coal inlet gradually increased. After the temperature exceeds $75^{\circ} \mathrm{C}$, the heat release intensity of different coal heights gradually increased with time, and the intensity of heat release coincides with the migration law of the high temperature point of the coal body height.
\end{abstract}

\section{INTRODUCTION}

Coal spontaneous combustion is a huge problem that troubles all coal mines in the world. More than $90 \%$ coal seams in China have a tendency to spontaneously combust. Coal spontaneous combustion seriously threatens human physical and mental health, the natural environment, and the safe production of coal mines, causing huge economic losses and waste of resources [1]. The cause of spontaneous combustion of coal seam is mainly the combined reaction of coal and oxygen, and the process is affected by many factors. Therefore, mastering the distribution law of oxygen consumption rate and heat release intensity in the process of spontaneous combustion of coal plays a very important role in preventing and controlling spontaneous combustion of coal seam.

Yang et al. [2] designed and built an experimental system for testing the spontaneous combustion characteristics of coal, as well as examined parameters such as the exothermic strength and thermal conductivity of coal spontaneous combustion at a low temperature $\left(<110^{\circ} \mathrm{C}\right)$. Cárdenas-Lea et al. [3] determined the relationship between the oxidation rate and the oxygen absorption tendency in the natural process of coal. Based on the Wiser chemical structure model, some experts and scholars have proposed the surface molecular model of self-burning coal and discussed the mechanism of spontaneous combustion of coal [4-9]. Zhu et al. [10] analyzed the relationship between the exothermic strength and temperature in the process of coal oxidation through the oxidation heating experiment. The exothermic strength was low before the critical temperature, and the exothermic strength increased sharply after the critical temperature. Sasaki et al. [11] estimated the heat release rate of coal based on the equivalent exposure time method, and predicted the danger degree of spontaneous combustion of coal stack based on the changes of temperature and oxygen concentration of coal seam exposed in air flow. Chen et al. [12] developed an experimental device for self-absorption of loose coal at high temperature, and concluded that the thermal convection effect has a great influence on the heat transfer in loose coal. Li et al. [13] simulated the spontaneous combustion process of coal by using the coal spontaneous combustion experimental furnace, and determined the evolution law of the accelerating point and high temperature region of coal autooxidation. Nordon [14] established an active unsteady spontaneous combustion model to predict the spontaneous combustion of coal. Jones [15] examined the solution model of the bituminous coal spontaneous combustion period. Liang et al. [16] examined the control equation for the shortest spontaneous combustion period of loose coal considering heat convection and conduction, and then provided its analytical solution. Feng [17] and Cudmore [18] used the combustible method to determine the oxygen consumption rate and heat release rate of coal. Liu et al. [19] studied the spontaneous combustion process of loose coal under the condition of constant air volume, and obtained the temporal and spatial evolution law of temperature and oxygen concentration. Glasser [20] predicted the spontaneous combustion tendency of coal by using the computer-controlled calorie-free thermal method. Pan et al. [21] comprehensively studied the change of CO and 
$\mathrm{O}_{2}$ concentration in the whole goaf, combined with numerical simulation results, and used multiple indicators to determine the scope of spontaneous combustion "three zones" in goaf with high accuracy. Lei et al. [22] established a 2-t experimental furnace for coal spontaneous combustion. Their experimental results demonstrate that it takes 27 days for the coal in Dafosi to rise from 19.8 to $96.89{ }^{\circ} \mathrm{C}$. Wen et al. [23] then established a 1.5 tones experimental furnace for coal spontaneous combustion. Based on that furnace, the effect of thermal boundary on the temperature distribution and spontaneous combustion period was examined by combining the gas flow equation for loose coal and CFD simulation.

Most of the previous studies have made a detailed analysis of a specific characteristic parameter in the process of coal spontaneous combustion, but few have carried out in-depth research on the characteristic parameters of coal spontaneous combustion process from two perspectives of time and space. In recent years, Li et al. [13] analyzed the temporal and spatial variation rules from the perspectives of high temperature point migration and index gas in the spontaneous combustion process of coal. However, due to the volume limitation of experimental equipment, the experimental simulation of the spontaneous combustion process in fire areas could not be well realized. Zhou [24] analyzed the change of characteristic parameters in the process of coal spontaneous combustion by simulating the spontaneous combustion situation in goaf, but the temperature rise was passive and did not reflect the experimental characteristics of spontaneous heating. In this paper, a large coal spontaneous combustion furnace was used to simulate the spontaneous combustion process of coal (from normal temperature to $140^{\circ} \mathrm{C}$ ), and the differences and laws of the heat released intensity and oxygen consumption rate in different areas and time in the spontaneous combustion process of coal are analyzed, so as to provide reference for further research on the multi-field coupling effect of coal spontaneous combustion.

\section{EXPERIMENTAL APPARATUS AND PROCESS}

\subsection{The experimental device}

This experiment uses the XK-VII large coal combustion firing test bench, the maximum loading capacity of 2 tones, the test bench mainly includes the furnace body, gas circuit device and monitoring system three parts, the furnace body is cylindrical, the maximum loading height of $200 \mathrm{~cm}$, the inner diameter of $120 \mathrm{~cm} .10 \sim 20 \mathrm{~cm}$ free space is reserved at the top and bottom respectively, to ensure that the inlet and outlet gas uniform, the top left with exhaust port. The outer wall of the furnace body has an insulation layer and a temperaturecontrolled water layer to ensure that the temperature of the incoming gas is roughly the same as the temperature of the coal sample inside the furnace and to maintain a good heat storage environment. The structure of the furnace body is shown in Figure 1.

\subsection{Collection and control of gas and temperature}

Experimental furnace from $0.05 \mathrm{~m}$ away from the furnace bottom, within every $0.2 \mathrm{~m}$ transverse and longitudinal cross distributed temperature measuring probe, each temperature probe $0.2 \mathrm{~m}$ apart, and set up along the central axis of each layer gas sampling tube, a total of 131 temperature distribution of the probe and 40 gas sampling points. Temperature measuring points were automatically controlled by computer, and the temperature of each measuring point was automatically updated and recorded every 30 minutes.

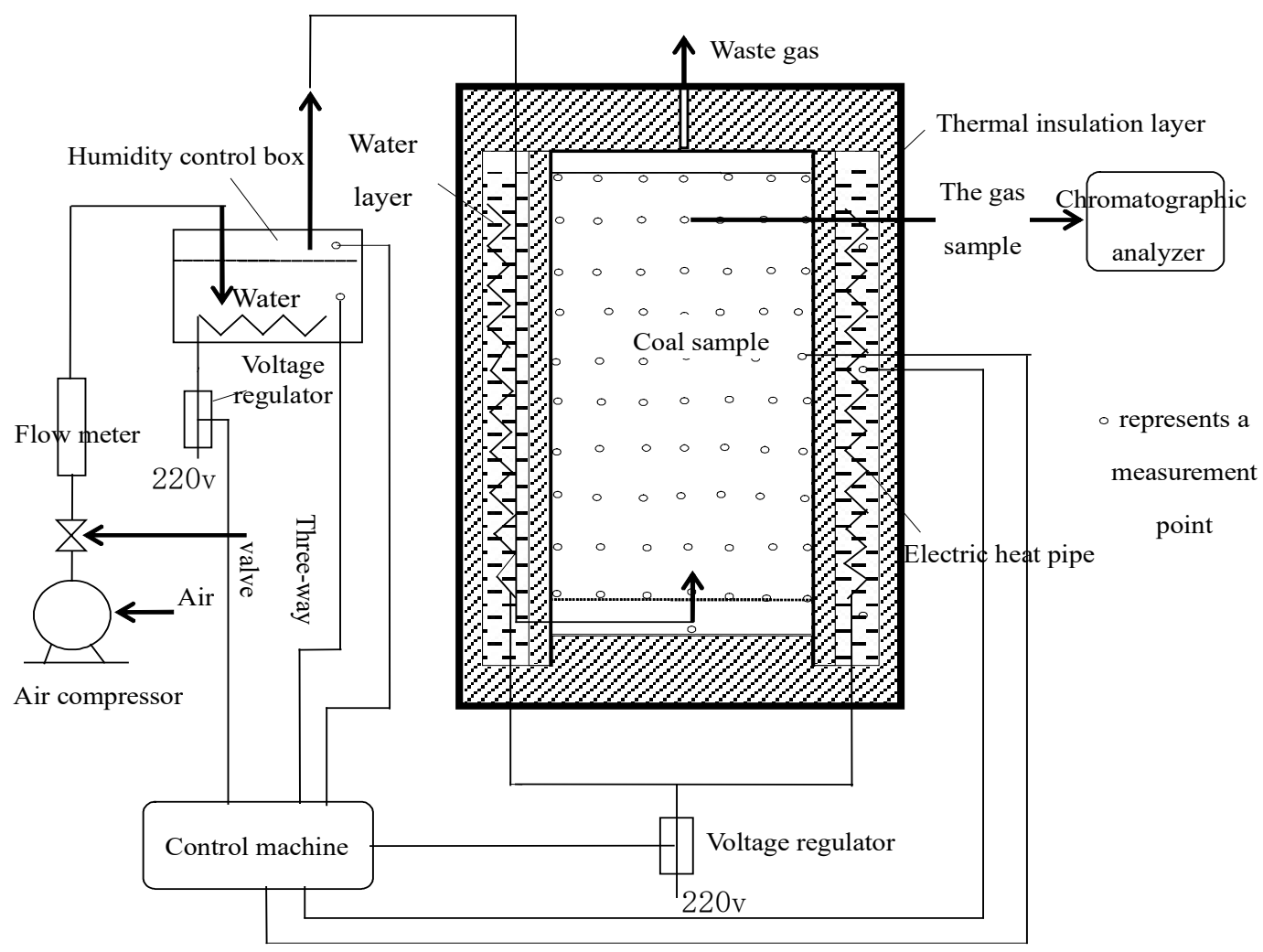

Figure 1. Structure diagram of coal spontaneous combustion experimental furnace 


\subsection{Experimental conditions and procedures}

The coal samples for the experiment were crushed into standard particle sizes by the mandible coal crusher. In order to avoid oxidation of the coal samples, the pulverized coal samples were put into the experimental furnace within 6 hours. The specific particle sizes and basic data of the coal samples are shown in Table 1, Table 2 and Table 3. Before the start of the experiment, check the tightness of the furnace body, whether the air supply system and temperature control monitoring system work normally. After ensuring the normal operation of the system, inject the dry air preheated in the temperature control water layer into the experimental furnace, and record the gas data every day from the normal temperature $\left(36^{\circ} \mathrm{C}\right)$ until it reaches $140^{\circ} \mathrm{C}$.

Table 1. Particle size of coal sample

\begin{tabular}{ccccccc}
\hline$"$ & +10 & $\begin{array}{c}-10, \\
+7\end{array}$ & $\begin{array}{c}-7, \\
+5\end{array}$ & $\begin{array}{c}-5, \\
+3\end{array}$ & $\begin{array}{c}-3, \\
+0.9\end{array}$ & -0.9 \\
\hline Mass (g) & 1.7 & 19.1 & 26.5 & 62 & 112.5 & 212.2 \\
$\begin{array}{c}\text { Frequency } \\
\text { (\%) }\end{array}$ & 0.004 & 0.044 & 0.061 & 0.143 & 0.259 & 0.489 \\
\hline
\end{tabular}

Note: the "+" in the table indicates that the filter is not passed, and the "-" indicates that the filter is passed

Table 2. Basic data of coal samples

\begin{tabular}{ccccccc}
\hline $\begin{array}{c}\text { Starting } \\
\text { temperature } /{ }^{\circ} \mathbf{C}\end{array}$ & $\begin{array}{c}\text { Average particle } \\
\text { size } / \mathbf{c m}\end{array}$ & $\begin{array}{c}\text { Coal sample } \\
\text { height } / \mathbf{c m}\end{array}$ & $\begin{array}{c}\text { Coal sample } \\
\text { weight } / \mathbf{k g}\end{array}$ & $\begin{array}{c}\text { Coal sample } \\
\text { volume } / \mathbf{c m}^{\mathbf{3}}\end{array}$ & $\begin{array}{c}\text { Void } \\
\text { ratio }\end{array}$ & $\begin{array}{c}\text { Air supply } \\
\text { volume } / \mathbf{m}^{\mathbf{3}} / \mathbf{h}\end{array}$ \\
\hline 36 & 2.08 & 141 & 1373.66 & 1582560 & 0.38 & 0.1 \\
\hline
\end{tabular}

Table 3. Proximate analysis and Ultimate analysis of pulverized coal

\begin{tabular}{cccccccccccc}
\hline \multirow{2}{*}{ Sample } & \multicolumn{4}{c}{ Proximate analysis (\%) } & \multicolumn{4}{c}{ Calorific value $\left.\mathbf{( M J} \cdot \mathbf{k g}^{-1}\right)$} & \multicolumn{4}{c}{ Ultimate analysis $\left(\mathbf{W}_{\text {ad }} / \mathbf{\%}\right)$} \\
& $\mathrm{M}_{\mathrm{ad}}$ & $\mathrm{A}_{\mathrm{ad}}$ & $\mathrm{V}_{\mathrm{ad}}$ & $\mathrm{FC}_{\mathrm{ad}}$ & $\mathrm{Q}$ gr,ad & $\mathrm{Q}_{\text {net,ad }}$ & $\mathrm{C}$ & $\mathrm{H}$ & $\mathrm{O}$ & $\mathrm{N}$ & $\mathrm{S}$ \\
\hline $\mathrm{ZX}$ & 9.54 & 13.88 & 39.10 & 37.48 & 28.32 & 24.11 & 80.11 & 3.03 & 14.64 & 1.92 & 0.30 \\
\hline
\end{tabular}

In the process of the experiment, the migration rule of the high temperature area of the central axis measuring point was shown in Figure 2.

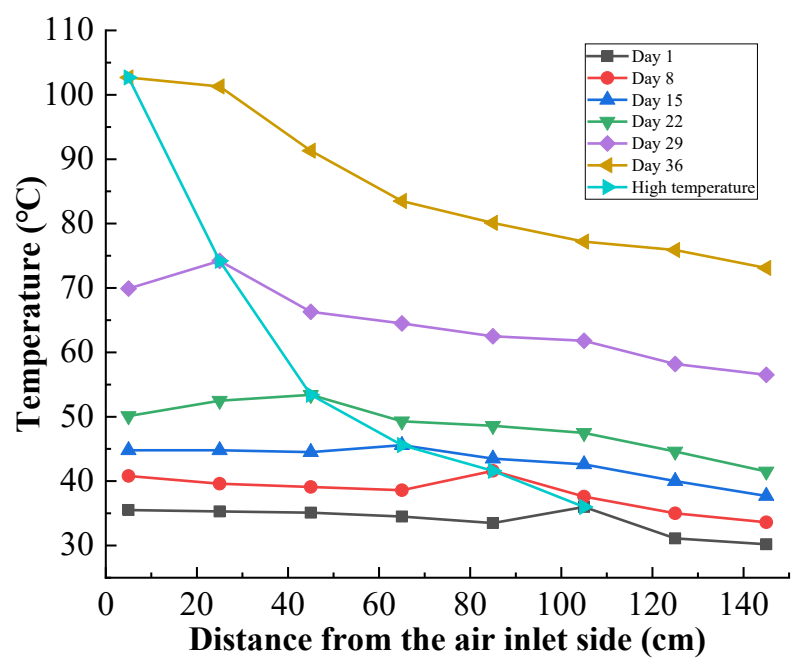

Figure 2. Relation diagram of temperature and height at center axis measuring point

Selecting the number of days in the process of selecting the high temperature points in different areas is shown below, it can be seen that at the beginning of the experiment, the high temperature area did not appear on the intake side with high oxygen concentration, but in the low oxygen concentration area of the upper layer of the coal body, with the advance and increase of temperature, the high temperature area gradually moved towards the inlet side. It took about 29 days for the temperature of the central axis to rise from the initial normal temperature to $75^{\circ} \mathrm{C}$, while it only took about 10 days for the temperature to rise from $75^{\circ} \mathrm{C}$ to $140^{\circ} \mathrm{C}$, and only $1 / 3$ of the time for the high temperature stage, which shows that the loose coal body is mainly oxidation heat storage in the low temperature stage, and the heat accumulation is a very long process. When the coal body heat storage environment reaches a certain state, the loose coal body enters the high temperature stage, high temperature stage is the violent stage of coal oxygen compound chemical reaction in loose coal body, so the coal temperature increases rapidly.

\section{ANALYSIS OF EXPERIMENTAL RESULTS}

In the process of coal spontaneous combustion, when the air volume was constant, the oxygen consumption rate and heat released intensity of each distribution point in the furnace body change with time and heat dissipation conditions, and the peak value gradually moved towards the air inlet side.

\subsection{Temporal and spatial distribution of oxygen consumption rate in coal spontaneous combustion}

Oxygen is an important index to measure the process of coal spontaneous combustion. The change of oxygen concentration at each measuring point in the furnace is mainly related to air flow, molecular diffusion, turbulent diffusion and oxygen consumption due to the action of coal oxygen. Fresh air is injected into the experiment, and the coal sample is subjected to coal-oxygen composite reaction. By measuring the oxygen concentration at different measuring points and at different time periods in the spontaneous combustion process of the coal sample, the oxygen consumption rate can be calculated as follows [25]:

$$
V_{O_{2}}^{0}(T)=\frac{Q \cdot C_{0}}{S\left(Z_{i+1}-Z_{i}\right)} \cdot \ln \frac{C_{i}}{C_{i+1}}
$$

where: $V_{O_{2}}^{0}(T)$ is the oxygen consumption rate at the standard air oxygen concentration $(21 \%), \mathrm{mol} /\left(\mathrm{cm}^{3} \cdot \mathrm{s}\right) ; Q$ is the available air quantity, $\mathrm{ml} / \mathrm{s} ; C_{0}$ is the oxygen concentration of fresh air, $\% ; S$ is the section area of the experimental furnace, $\mathrm{cm}^{2} ; Z_{i+1}-Z_{i}$ is the height of coal sample, $\mathrm{cm} ; C_{i}$ 
and $C_{i+1}$ respectively represent the oxygen concentration at point $i$ and point $i+1, \%$.

Figures 3 and 4 show the evolution of the oxygen consumption rate in time and space during coal spontaneous combustion.

\subsubsection{Relationship between oxygen consumption rate and} height

It can be seen from Figure 3 that the oxygen consumption rate was lower when the coal temperature was below $75^{\circ} \mathrm{C}$, and the maximum oxygen consumption rate was distributed in the low oxygen concentration area far from the inlet side. As the temperature rises, the oxygen consumption rate gradually increased, and the position of the maximum oxygen consumption rate moved towards the inlet side. The oxygen consumption rate in the area with a low oxygen concentration remained at a low level. It can also be seen from Figure 3 that the oxygen consumption rates in different regions were positively correlated with their heating rates, and the spatial distribution law of the locations where the maximum oxygen consumption rate appears coincided with the transport law of the high-temperature region.

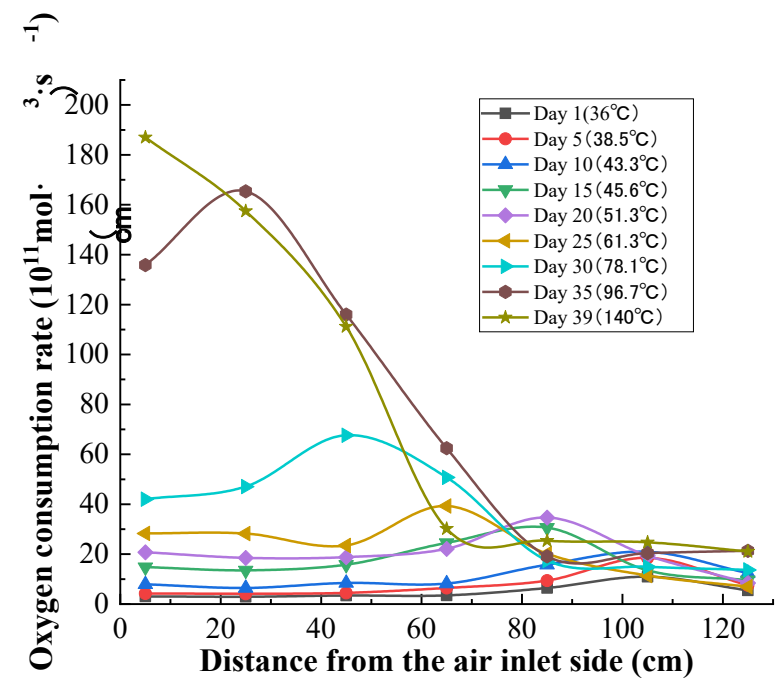

Figure 3. Relationship between oxygen consumption rate and height at central axonometric point

\subsubsection{Relationship between oxygen consumption rate and time}

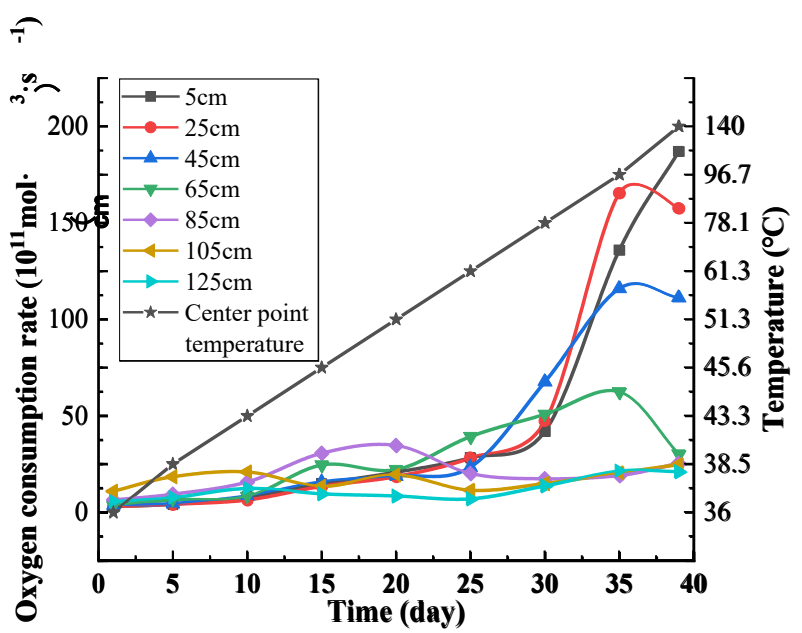

Figure 4. Relation between oxygen consumption rate and time at center axis measuring point
Figure 4 shows the relationship between oxygen consumption rate and time at the measuring point of the central axis in the process of coal spontaneous combustion. In the region of low oxygen concentration (far away from the inlet side), the oxygen consumption rate reached its peak at the beginning of the experiment. After the temperature rose, the high temperature region moved down gradually, and the oxygen consumption rate in the low oxygen concentration region decreased first, then slowly increased and become stable. When the coal temperature was below the critical temperature $\left(65 \sim 75^{\circ} \mathrm{C}\right)$, the oxygen consumption rate of coal sample increased slowly. When the coal temperature exceeded this temperature, the oxygen consumption rate increased significantly. When the coal temperature exceeded the dry crack temperature $\left(90 \sim 100^{\circ} \mathrm{C}\right)$, the oxygen consumption rate increased sharply. In the area with high oxygen concentrations which closed to the inlet side, before the temperature reaches $100^{\circ} \mathrm{C}$, the oxygen consumption rate was positively correlated with the temperature. After the temperature rose to $100^{\circ} \mathrm{C}$, higher-temperature area shifted to the inlet side, and the oxygen consumption rate at the bottom reached its maximum value. The heating rate of coal accelerates, and the loose coal samples approached the spontaneous combustion point.

\subsection{Spatial and temporal distribution of exothermic intensity in spontaneous combustion of coal}

The spontaneous combustion heating of loose coal is mainly caused by the combined reaction of coal and oxygen and the heat storage environment. In other words, when the heat release intensity of the experimental coal sample under the spontaneous combustion heating, condition is compared with the heat dissipation condition of the surrounding environment, when the heat release intensity is greater than the heat loss of the coal sample, the experimental coal will heat up.

During the heating process of spontaneous combustion of coal samples, the temperature at each point of the experimental coal and the oxygen concentration at the control center were measured. According to the principle of energy conservation and the method of heat transfer, the calculation formula of coal heat release intensity can be deduced [25]:

$$
\begin{aligned}
q\left(T, C_{O_{2}}\right)=S_{c} \cdot & \frac{\partial T}{\partial \tau}+\frac{\bar{Q}}{n} \cdot \frac{\rho_{\mathrm{g}}}{\rho_{c}} \cdot S_{\mathrm{g}} \cdot \frac{\partial T}{\partial z}-\frac{\lambda_{c}}{\rho_{c}} \\
& \cdot\left(2 \frac{\partial^{2} T}{\partial r^{2}}+\frac{\partial^{2} T}{\partial z^{2}}\right)
\end{aligned}
$$

where: $q\left(T, C_{\mathrm{O}_{2}}\right)$ is the oxidative exothermic strength of coal, $J /(\mathrm{g} \cdot \mathrm{s}) ; T$ and $\tau$ are respectively the temperature and oxidation time of loose coal, ${ }^{\circ} \mathrm{C}, s ; \bar{Q}$ the strength of air seeping through the loose coal, $\mathrm{cm}^{3} /\left(\mathrm{cm}^{2} \cdot \mathrm{s}\right)$; is the thermal conductivity of a loose coal, $\mathrm{J} /\left(\mathrm{cm} \cdot{ }^{\circ} \mathrm{C} \cdot \mathrm{s}\right) ; r$ and $z$ are radial and longitudinal coordinates, $\mathrm{cm} ; \rho_{c}, \rho_{\mathrm{g}}, S_{c}$ and $S_{\mathrm{g}}$ are respectively the density and specific heat capacity of loose coal and air, $\mathrm{g} / \mathrm{cm}^{3}, \mathrm{~J} / \mathrm{g} \cdot{ }^{\circ} \mathrm{C}$.

Figure 5 and Figure 6 showed the evolution rule of exothermic intensity in time and space during spontaneous combustion of coal.

\subsubsection{Relationship between heat intensity and height}

As can be seen from Figure 5, before the coal temperature reached the critical temperature, the temperature rose slowly and the exothermic intensity was low. The peak of exothermic 
intensity was mainly concentrated in the upper part of the coal body, and the heat intensity under low temperature condition was always relatively stable. This is because the coal upper initial heat storage environment was better, heat accumulation, high heat released intensity. With the increase of coal temperature, the exothermic strength was enhanced as a whole, and the difference between the exothermic strength at high temperature point and that in other areas of coal body was larger. The exothermic intensity on the inlet side first reached the spontaneous combustion point, and the region where the exothermic intensity was gradually moved to the inlet side. The occurrence sequence of the exothermic intensity peak was consistent with the change sequence of the high temperature region.

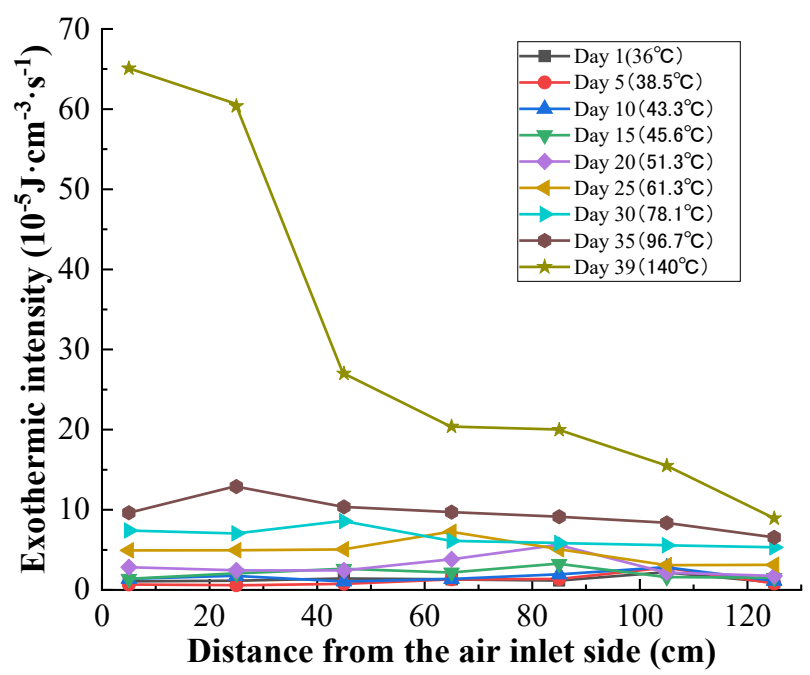

Figure 5. Relationship between heat release intensity and height of central axonometric point

\subsubsection{Relationship between heat intensity and time}

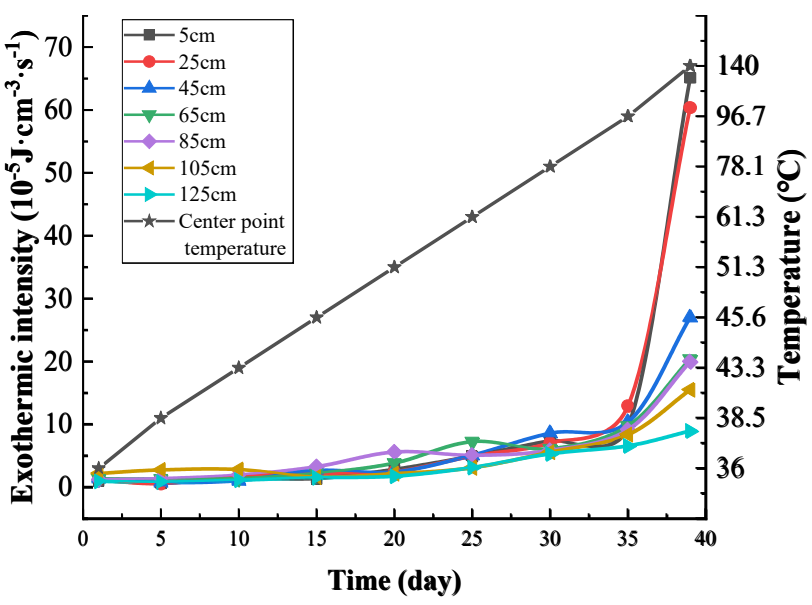

Figure 6. Relationship between heat release intensity and time at central axonometric point

As can be seen from Figure 6, in the early stage of the experiment, the exothermic strength tended to be stable and the rising speed was slow, and the peak of exothermic strength was mainly concentrated in the upper part of the coal body. This was because the air leakage intensity on the upper part of the coal body was small at the early stage of the experiment, and the heat concentration was better. As the temperature increased, the peak exothermic intensity gradually moved downward, and the upper exothermic intensity dropped slightly before the critical temperature. After the coal temperature exceeded the critical temperature, the exothermic intensity increased sharply, and the closer it was to the inlet, the faster the exothermic intensity increased after the critical temperature, and the greater the difference between the exothermic intensity before and after the critical temperature.

\subsection{Results discussion}

Whether the loose coal body can spontaneously ignite mainly depends on the heat storage conditions, that is, the heat release strength of the coal body and the size of the thermal strength of the surrounding environment, in a good heat storage environment, the oxidation and heat release intensity of the coal body is greater than the heat lost by the environment, the coal body will heat up [26].

However, due to the coupling effect of air seepage field, oxygen concentration and temperature field in loose coal, the unsteady change is essentially due to the contact between a large number of loose coal and oxygen. The thermal conductivity of coal is poor, and the continuous accumulation of heat leads to the gradual heating of coal, thus accelerating the reaction [27, 28]. The combined reaction of coal and oxygen in loose coal is mainly chemical reaction, which produces more heat. The coal at different heights has different heat storage conditions. In the middle and lower regions near the air inlet, the coal has good oxidation heat storage conditions and high oxygen concentration, and the coal temperature rises rapidly. Especially, when the maximum coal temperature exceeds $75^{\circ} \mathrm{C}$, the coal temperature at the inlet side increases rapidly within $2 / 10$ of the coal height. The accumulated heat heats the surrounding coal, resulting in an increase in gas density, while the difference in temperature between the inside and outside of different areas within the loose coal increases the amount of oxygen the coal gradually consumes. The high temperature zone leads to the damage of the internal structure of the coal body, which further develops the cracks and voidage in the coal body, and forms the phenomenon of "self-absorption" oxygen in the high temperature zone, and changes the distribution of oxygen concentration field in the coal body under the constant air leakage state. Literature studies have also shown that due to the presence of gases in pore areas between particle sizes of loose coal. The heat transfer effect in the hot heat source region leads to the temperature gradient field in different regions of the coal and finally leads to the gradient effect of the gas density field in the loose coal.

\section{CONCLUSIONS}

1) In the process of spontaneous combustion of loose coal bodies, the high temperature point first appears in the upper $7 / 10$ of the coal body, when the temperature is lower than the critical temperature (about $75^{\circ} \mathrm{C}$ ), the high temperature point moves slowly; after exceeding the critical temperature, it moves rapidly to the high oxygen concentration area on the inlet side, and the bottom of the coal seam first reaches the spontaneous combustion point, while the temperature change of the surrounding measurement points varies with the height of the coal body and the intensity of air leakage in different temperature stages.

2) The distribution pattern of the oxygen consumption rate 
in time and space of the loose coal body shows that: the oxygen consumption rate of the coal body rises slowly at the beginning and decreases as the temperature gradually moves downwards, coinciding with the transport pattern of the high temperature point, the oxygen consumption rate of the upper part of the coal body increases less over time, while the oxygen consumption rate of the high oxygen concentration area on the inlet side increases more before and after.

3) From the distribution pattern of the exothermic intensity of the loose coal body in time and space, it can be seen that: the exothermic intensity of the coal body is consistent with the transport of the high temperature point, the exothermic intensity of the inlet side has a large span before and after and reaches the spontaneous combustion point first, the peak of the exothermic intensity can be judged according to the location of the high temperature point of the detected coal seam in the actual observation, the research results are more relevant and directional for the use of the actual project.

\section{REFERENCES}

[1] Jin, Y.F., Guo, J., Wen, H., Liu, W.Y., Wang, K., Ma, X.F. (2015). Experimental study on the high temperature lean oxygen oxidation combustion characteristic parameters of coal spontaneous combustion. Journal of China Coal Society, 40(3): 596-602. https://doi.org/10.13225/j.cnki.jccs.2014.0626

[2] Yang, Y., Li, Z., Si, L., Hou, S., Li, Z., Li, J. (2018). Study on test method of heat release intensity and thermophysical parameters of loose coal. Fuel, 229: 3443. https://doi.org/10.1016/j.fuel.2018.05.006

[3] Cárdenas-Leal, J.L., Vázquez, J., Barreda, D.G.G., López-Alemany, P.L., Villares, P., Jiménez-Garay, R. (2009). On the glass-crystal transformation kinetics by using differential scanning calorimetry under nonisothermal regime: Application to the crystallization of the Ag0. 16As0. 46Se0. 38 semiconductor glass. Thermochimica Acta, 484(1-2): 70-76. https://doi.org/10.1016/j.tca.2008.11.014

[4] Xu, J.C., Zhang, X.H., Wen, H., Deng, J. (2000). Procedure of reaction between coal and oxygen at low temperature and calculation of its heat emitting intensit. Journal of China University of Mining \& Technology, 29(3): 253-257. https://doi.org/10.3321/j.issn:10001964.2000.03.007

[5] Pinchuk, V.A., Sharabura, T.A., Kuzmin, A. (2016). Experimental investigation of thermal conductivity and heat capacity of coal-water fuel. International Journal of Energy for a Clean Environment, 17(2-4): 165-185. https://doi.org/10.1615/InterJEnerCleanEnv.201601941 1

[6] Wang, H., Dlugogorski, B.Z., Kennedy, E.M. (2002). Thermal decomposition of solid oxygenated complexes formed by coal oxidation at low temperatures. Fuel, 81(15): 1913-1923. https://doi.org/10.1016/S00162361(02)00122-9

[7] Zhang, G.S., Xie, Y.M., Gu, J.M. (2003). Infrared spectral analysis of microstructure change during the coal spontaneous oxidation. Journal of China Coal Society, 28(5): 473-476. https://doi.org/10.3321/j.issn:0253-9993.2003.05.006

[8] Shi, T., Deng, J., Wang, X.F., Wen, Z.Y. (2004). Mechanism of spontaneous combustion of coal at initial stage. Ranliao Huaxue Xuebao, 32(6): 652-657.

[9] Luo, M., Yi, Y., Cai, J., Liu, K., Wang, C., Wang, Q. (2018). Comparison of the performance of iron ore and synthetic iron-based oxygen carrier for chemical looping combustion of coal. International Journal of Energy for a Clean Environment, 19(3-4): 157-174. https://doi.org/10.1615/InterJEnerCleanEnv.201802537 0

[10] Zhu, J.F., Xu, Y.M., Guo, W.J., Duan, J.M. (2016). Experimental study on exothermal characteristics of coal spontaneous combustion. J. Journal of North China University of Science and Technology, 13(1): 1-8.

[11] Sasaki, H., Miyakoshi, H., Otsuka, K. (1997). Spontaneous combustion of coal in the low temperature range. Application of exposure equivalent-time to numerical analysis. Nippon Kogyo Kaishi, 103(11): 771775.

[12] Chen, X.K., Li, H.T., Wang, Q.H., Zhang, H.W. (2015). Development and application of experimental device for studying oxygen absorption by high temperature loose coal. China Safety Science Journal, 25(10): 29-34. https://doi.org/10.16265/j.cnki.issn10033033.2015.10.005

[13] Li, L., Chen, J.C., Jiang, D.Y., Fan, J.X., Gao, Y.L. (2016). Experimental study on temporal variation of high temperature region and index gas of coal spontaneous combustion. Journal of China Coal Society, 41(2): 444450. https://doi.org/10.13225/j.cnki.jccs.2015.0355

[14] Nordon, P. (1985). Spontaneous combustion interactive heat and mass transfer driven by a chemical reaction. Third Australasian Conference on Heat \& Mass Transfer, Aust: St Leonards. 363-370, 1985

[15] Jones, J.C. (2000). On the role of times to ignition in the thermal safety of transportation of bituminous coals. Fuel, 79(12): 1561-1562.

[16] Liang, Y., Song, S., Luo, H., Lin, Q., Feng, W., Tian, F. (2015). An analytic solution of coal spontaneous combustion period calculation model. J China Coal Soc., 40(9): 2110-2116.

[17] Feng, K.K. (1985). Spontaneous combustion of Canadian coals. CIM Bull. (Canada), 78(5): 71-75.

[18] Cudmore, J.F. (1988). Spontaneous combustion of coal and mine fires: by SC Banerjee (Editor), AA Balkema, Rotterdam, The Netherlands, 1985, xii+ 168 pp., Dfl. 68, 25 (hardback). J. International Journal of Coal Geology., 9(4): 397-398.

[19] Liu, W.Y., Wen, H., Yan, X.B. (2017). Spatial-temporal variation of temperature and oxygen concentration in coal spontaneous combustion process. Journal of Xi'an University of Science and Technology, 37(5): 636-42. https://doi.org/10.13800/j.cnki.xakjdxxb.2017.0506

[20] Glasser, B.K.S.N. (1988). Critical temperatures of some Turkish coals due to spontaneous combustion. Journal of Mines Metals \& Fuels, 36(9): 434-436.

[21] Pan, R., Cheng, Y., Yu, M., Lu, C., Yang, K. (2013). New technological partition for "three zones" spontaneous coal combustion in goaf. International Journal of Mining Science and Technology, 23(4): 489493. https://doi.org/10.1016/j.ijmst.2013.07.005

[22] Lei, C., Deng, J., Cao, K., Ma, L., Xiao, Y., Ren, L. (2018). A random forest approach for predicting coal spontaneous combustion. Fuel, 223: 63-73. https://doi.org/10.1016/j.fuel.2018.03.005

[23] Wen, H., Yu, Z., Deng, J., Zhai, X. (2017). Spontaneous 
ignition characteristics of coal in a large-scale furnace: an experimental and numerical investigation. Applied Thermal Engineering, 114: 583-592. https://doi.org/10.1016/j.applthermaleng.2016.12.022

[24] Zhou, P.L. (2017). Spatial-temporal evolution mechanism of residual coal oxidation warming in goaf, $\mathrm{PhD}$. University of Science and Technology Beijing.

[25] Bao, Q.G., Wen, H., Wang, X.L., Xu, J.C. (2002). Theory and Control Technology of Coal Spontaneous Combustion, Beijing: Coal Industry Press, 72-88.

[26] Wen, H., Xu, M.G., Li, L., Dai, A.P. (2003). Analysis of heat-accumulating process of coal self-ignition and its effect factor. Journal of Liaoning Technical University
(Natural Science Edition), 22(2): 151-154.

[27] Ma, H.P., Lu, W., Wang, D.M., Dai, G.L., Zhong, X.X. (2006). Research on physical adsorbed oxygen in coal spontaneous combustion processing. Coal Science and Technology,

34(7):

26-29.

https://doi.org/10.3969/j.issn.0253-2336.2006.07.009

[28] Zhang, L., Pan, Z., Shang, L., Dong, L. (2018). Thermoeconomic analysis of organic Rankine cycle (orc) with co 2 capture system for coal-fired power plant waste heat recovery. International Journal of Energy for a Clean Environment, 19(3-4):

303-322. https://doi.org/10.1615/InterJEnerCleanEnv.201802538 1 